\title{
PENERAPAN RAGAM HIAS FLORA PADA KERAMIK DALAM MATA PELAJARAN SENI BUDAYA BIDANG SENI RUPA BAGI SISWA SMP NEGERI 2 BANGKALA BARAT KABUPATEN JENEPONTO
}

\author{
Mega Selfia $\mathbf{H}^{1}$, Yabu.. ${ }^{2}$ \\ Prodi Pendidikan Seni Rupa, Fakultas Seni dan Desain Universitas Negeri Makassar \\ megadgbintang@gmail.com \\ yabu.m@unm.ac.id
}

\begin{abstract}
ABSTRAK
Penelitian ini bertujuan untuk mendeskripsikan langkah-langkah penerapan ragam hias flora pada keramik dalam Mata Pelajaran Seni Budaya Bidang Seni Rupa di kelas VIII K SMP Negeri 2 Bangkala Barat Kabupaten Jeneponto. Jumlah sampel dalam penelitian ini adalah 1 kelas yang terdiri dari 24 siswa kelas VIII K. Teknik pengumpulan data dilakukan dengan teknik observasi, wawancara, tes praktik dan dokumentasi. Sedangkan sasaran penelitiannya adalah kegiatan praktik penerapan ragam hias flora pada bahan keras terutama pada keramik di kelas VIII K SMP Negeri 2 Bangkala Barat Kabupaten Jeneponto. Hasil yang diperoleh dari penelitian ini adalah sebagai berikut: 1) Siswa melakukan praktik sesuai dengan langkah-langkah penerapan ragam hias flora pada keramik. 2) Siswa megalami kesulitan dalam membuat desain motif ragam hias flora, dan mewarnai motif ragam hias pada keramik. Sesuai sengan hasil penelitian yang telah dilakukan diajukan saran-saran sebagai berikut: 1) Diharapkan kepada Guru agar tetap memberikan praktik-praktik dalam proses pembelajaran, khususnya praktik penerapan ragam hias flora baik pada keramik maupun media lain agar siswa dapat menghargai kesenian nusantara yang ada disekitar kita. 2) Diharapkan kepada siswa SMP Negeri 2 Bangkala Barat agar dapat termotivasi dengan pelaksanaan kegiatan praktik penerapan ragam hias flora khususnya pada keramik lebih baik lagi.
\end{abstract}

\section{Kata Kunci: Dekoratif; Bunga}

\begin{abstract}
ABSTRACK
This Research aim to describe the step for applying flora to ceramics in cultural arts in the cultural arts course in the field of fine arts in class VIII K SMP Negeri 2 Bangkala Barat jeneponto Regency. The number of samples in this study was 1 class consisting of 24 students of class VIII K. Data collection techniques were carried out by observation, interviews, practice tests and documentation. While the practice of applying flora to hard materials, especially to ceramics in class VIII K SMP Negeri 2 Bangkala Barat Jeneponto regency. The results obtained from this study are as follows: 1) Students practice according to the ateps of applying decorative flora to ceramics. 2) Students have difficult making designs of decorative flora motifs, and coloring decorative motifs on ceramics. In accordance with the results of the research that has been carried out the following suggestions are proposed: 1) It has hoped that the theacher will continiue to provide practices in the learning process, especially the practice of applying flora to ceramics and other media so that students can appreciate the archipelago arts around we. 2) It is hoped that students in SMP Negeri 2 Bangkala Barat in order to be motivated by the implementation of practical activities in applying flora, especially on ceramics, is better.
\end{abstract}

Keyword: Decorative; Flora, 


\section{PENDAHULUAN}

Salah satu kegiatan yang dapat menumbuhkan rasa estetik dan artistik dalam diri siswa pada umumnya adalah praktik langsung, teruama dalam pembelajaran penerapan ragam hias pada benda keramik. Dengan memberikan teori pengantar sebagai acuan siswa kemudian segera melakukan kegiatan praktik dapat membuat siswa lebih bersemangat mengikuti kegiatan pembelajaran. Sudah menjadi tindakan andalan seorang guru dalam proses pembelajaran untuk membantu siswa memahami pembelajaran yang diberikan melalui praktik, terutama pelajaran seni rupa terkhusus dalam program kurikulum 2013.

Dalam pembelajaran seni rupa siswa akan tertarik mempelajari sesuatu yang belum pernah mereka temukan dalam buku pelajaran atau belum pernah diajarkan oleh guru mata pelajaran bersangkutan. Peneliti telah mencari praktik yang mudah dilakukan oleh siswa SMP Negeri 2 Bangkala Barat dan diharapkan praktik tersebut dapat menarik perhatian siswa, dan peneliti menemukan penerapan ragam hias flora pada keramik sebagai solusinya.

Salah satu ragam hias yang banyak diterapkan pada benda-benda hiasan adalah ragam hias flora. Motif ragam hias ini merupakan motif yang paling sering dipakai oleh siswa-siswi SMP karena motifnya yang sudah familiar bagi siswa, meskipun faktanya masih belum mengenal dengan baik motifmotif flora. Penerapan ragam hias flora ini diharapkan mampu mendorong krestifitas siswa dalam menentukan motif ragam hias, warna dan komposisi.

SMP Negeri 2 Bangkala Barat yang letak wilayahnya dekat dengan kota Takalar penghasil keramik (gerabah) tidakmempersulit siswa untuk menyiapkan bahan dan alat untuk penerapan ragam hias. Selain di Takalar siswa masih dapat menemukan keramik di pasarpasar di Kecamatan. Bangkala Barat.

Berdasarkan uraian di atas, penulis tertarik meneliti penerapan ragam hias flora pada keramik karena penelitian tentang ragam hias flora apalagi penerapannya pada bahan keras berupa keramik masih jarang dilakukan. Pada penelitian penerapan ragam hias flora pada keramik peneliti berharap dapat memberikan pengalaman praktik yang bermanfaat bagi pengetahuan siswa mengenai keramik dan ragam hias. Penelitian ini juga diharapkan dapat memberikan pengetahuan kepada siswa mengenai alat dan bahan serta langkahlangkah dalam penerapan ragam hias flora pada keramik. Bukan hanya pengetahuan mengenai jenis-jenis ragam hias flora tetapi juga mengenalkan siswa kepada kriya keramik yang merupakan budaya yang harus tetap dilestarikan.

Dalam kurikulum 2013 pada kompetensi dasar "4.3 Menerapkan ragam hias flora, fauna dan geometrik pada kriya dengan berbagai teknik dari bahan keras". seperti yang tertera dalam buku acuan pelajaran Seni Budaya SMP/MTS Kelas VIII Semester 2 pada Bab 1 Penerepan Ragam Hias pada Bahan Keras, penulis berinisiatif untuk memberikan praktik bagi siswa kelas VIII K SMP Negeri 2 Bangkala Barat yang tidak sempat didapatkan siswa di sekolah dengan menerapkan ragam hias flora pada keramik melalui teknik pengecatan.

Ragam hias flora yang menjadi motif yang banyak digambar oleh siswa SMP karena kemudahan menemukan referensi dan dapat ditemukan dalam lingkup sekolah. Teknik pengecatan yang sudah dapat dilakukan oleh siswa SMP akan mampu menumbuhkan kreatifitas siswa, sedangkan untuk bahan yang digunakan, yaitu keramik cukup mudah didapatkan di pasar-pasar yang ada di Jeneponto.

\section{METODE PENELITIAN}

Penelitian ini merupakan jenis penelitian evaluasi pembelajaran untuk materi penerapan ragam hias flora pada keramik. Berdasarkan tarafnya, penelitian ini merupakan penelitian deskriptif dan berdasarkan teknik analisis datanya penelitian ini merupakan penelitian kualitatif. Penelitian ini termasuk penelitian evaluatif dengan taraf deskriptif kualitatif. 
Penelitian ini dilakukan di SMP Negeri 2 Bangkala Barat yang beralamat di Buludoang, Desa Tuju, Kecamatan. Bangkala Barat, Kabupaten. Jeneponto, Sulawasi Selatan.

Variabel adalah objek yang akan diteliti. Berdasarkan judul dari penelitian ini yakni "Penerapan Ragam Hias Flora Pada Keramik dalam 'Mata Pelajaran Seni Budaya Bidang Seni Rupa Bagi Siswa Kelas VIII K SMPN 2 Bangkala Barat Kabupaten Jeneponto", yang menjadi variabel penelitian adalah langkahlangkah penerapan ragam hias flora pada keramik dalam mata pelajaran seni budaya bidang seni rupa bagi siswa kelas VIII $\mathrm{K}$ SMPN 2 Bangkala Barat Kabupaten Jeneponto.

Desain penelitian pada penelitian ini menggunakan desain penelitian tindakan kelas. Untuk menghindari kesalahpahaman atau ketidakjelasan terhadap penelitian ini maka perlu adanya definisi operasional variabel. Definisi operasional variabel akan dijelaskan sebagai berikut:

Langkah-langkah penerapan ragam hias flora pada keramik dalam mata pelajaran seni budaya bidang seni rupa bagi siswa kelas VIII K SMPN 2 Bangkala Barat Kabupaten Jeneponto merupakan kegiatan praktik yang dicapai oleh siswa kelas VIII K SMPN 2 Bangkala Barat yang berdasarkan, kriteria yang tercermin pada indikator: (1) gagasan/ide kreasi, (2) kreativitas, (3) keindahan, (4) kerapihan.

Menurut Iskandar (2008: 68), populasi adalah keseluruhan subjek penelitian yang dapat terdiri dari manusia, benda, hewan, tumbuh- tumbuhan, gejala-gejala, nilai tes atau peristiwa-peristiwa sebagai sumber data yang memiliki karakteristik tertentu di dalam suatu penelitian. Dengan demikian, yang menjadi populasi penelitian ini adalah keseluruhan siswa kelas VIII SMPN 2 Bangkala Barat Kabupaten Jeneponto. Siswa kelas VIII tersebut terdiri atas 3 kelas, yakni: Kelas VIII/A, kelas VIII/B dan kelas VIII/K.

Teknik pengambilan sampel pada penelitian ini menggunakan teknik simple random sampling dengan tanpa memandang rata dari populasi tersebut atau kata lain semua populasi dianggap homogen. Cara pengambilan sampel adalah dengan mengundi nama kelas. Kelas yang keluar itulah yang akan dijadikan sampel. Sampel yang diambil adalah satu kelas. Dengan demikian sampel pada penelitian ini adalah kelas VIII K. Jadi total sampel adalah 26 siswa. Namun pada saat melakukan wawancara ada 2 orang siswa yang tidak hadir sehingga jumlah yang diteliti sebanyak 26 siswa.

Untuk mendapatkan data yang akurat tentang Penerapan Ragam Hias Flora Pada Keramik Bagi Siswa kelas VIII K SMP Negeri 2 Bangkala Barat, maka cara pengumpulan data yang dilakukan adalah dengan mengunakan teknik tes, observasi dan dokumentasi. Tes yang digunakan berupa tes praktik. Tes yang digunakan dalam penelitian ini berupa tes praktik dengan prosedur yang ditempuh peneliti adalah mengadakan penugasan kepada siswa. Tes praktik ini dilakukan untuk mengetahui apakah siswa menggunakan teknik dan langkah-langkah yang tepat dalam menerapkan ragam hias flora pada keramik. Dalam rangka penelitian ini, siswa diberi tugas memberi hiasan atau ornamen dengan corak flora pada keramik dengan teknik pengecatan.

Cara yang ditempuh dalam pemberian tugas tersebut disesuaikan dengan jadwal mata pelajaran seni budaya. Peneliti mengadakan pengamatan langsung pada objek yang diteliti dalam kegiatan pelaksanaan penerapan ragam hias flora pada kelamik di kelas VIII K SMP Negeri 2 Bangkala Barat.

Teknik dokumentasi ini dilakukan untuk memperoleh data dokumen berupa gambar atau foto. Data ini merupakan data yang berkaitan dengan penelitian. Data yang diperoleh merupakan data yang dapat menunjang proses dan hasil penelitian. Alasan memilih cara ini karena dianggap sebagai salah satu cara untuk memperoleh data secara tepat, cepat dan efisien.

Teknik wawancara ini dilakukan untuk memperoleh informasi berupa ide atau data dari objek yang diteliti, yang berhubungan dengan penerapan ragam hias flora pada keramik dalam pelajaran seni budaya bidang 
Mega Selfia $\mathbf{H}^{1}$, Yabu. M, PENERAPAN RAGAM HIAS FLORA PADA KERAMIK DALAM MATA PELAJARAN SENI BUDAYA BIDANG SENI RUPA BAGI SISWA SMP NEGERI 2 BANGKALA BARAT KABUPATEN JENEPONTO

seni rupa terhadap siswa kelas VIII K SMPN 2 Bangkala Barat. Wawancara dilakukan dengan memberikan lembar observasi wawancara kepada siswa dan bertanya secara langsung kepada guru seni budaya SMP Negeri 2 Bangkala Barat.

Untuk mengetahui langkah-langkah penerapan ragam hias flora pada keramik bagi siswa kelas VIII K SMP Negeri 2 Bangkala Barat teknik analisis data yang digunakan dalam penelitian ini adalah deskriptif kualitatif dengan persentase (\%). Data yang diperoleh dengan menggunakan teknik kualitatif adalah data yang diperoleh dari hasil data observasi, wawancara, tes praktik dan dokumentasi.

\section{HASIL DAN PEMBAHASAN Hasil}

Pada bab ini, peneliti mendeskripsikan secara rinci hasil penelitian tentang langkahlangkah penerapan ragam hias flora pada keramik dalam mata pelajaran seni budaya bidang seni rupa bagi siswa kelas VIII K SMP Negeri 2 Bangkala Barat Kabupaten Jeneponto.

Sebelum mengadakan kegiatan praktik pada pertemuan kedua, pada pertemuan pertama guru seni budaya memberikan teori dan pemahaman kepada siswa mengenai alat dan bahan serta media penerapan ragam hias flora pada keramik serta langkah-langkah yang harus dilakukan untuk menghasilkan sebuah karya. Selanjutnya guru membagi siswa menjadi beberapa kelompok dan menugaskan setiap kelompok menyediakan alat dan bahan untuk kegiatan praktik pada pertemuan berikutnya.

Berikut alat dan bahan yang ditugaskan kepada siswa secara berkelompok:

1. Buah keramik (gerabah) untuk setiap kelompok

2. Kertas HVS

3. Pensil dan 3 buah kuas

4. Cat poster (dengan catatan warna sesuai keinginan setiap kelompok)

5. Gelas aqua bekas untuk mencampur warna dan membersihkan kuas.
6. Kertas kardus untuk pengalas meja agar cat tidak merembes di meja.

Berikut pembagian kelompok kelas VIII SMP Negeri 2 Bangkala Barat untuk kegiatan praktik:

Tabel 4. Daftar Nam Kelompok Praktik

\begin{tabular}{|c|l|}
\hline No & \multicolumn{1}{|c|}{\begin{tabular}{c}
\multicolumn{1}{|c|}{ Kama Anggota } \\
Kelompok
\end{tabular}} \\
\hline 1 & $\begin{array}{l}\text { Winda } \\
\text { Nur Fatwa Rahmadani } \\
\text { Melly Amaliah. }\end{array}$ \\
\hline 2 & $\begin{array}{l}\text { Novarina } \\
\text { Nurfadillah Yusran Suci } \\
\text { Fadillah Putri Dillah. }\end{array}$ \\
\hline 3 & $\begin{array}{l}\text { Muhammad Khasiron } \\
\text { Herlan Ananda Putra } \\
\text { Muhammad Dedi }\end{array}$ \\
\hline 4 & $\begin{array}{l}\text { Mirna, Lisa, } \\
\text { Maya Andriani Windy } \\
\text { Shafira Nur Mareta }\end{array}$ \\
\hline 5 & $\begin{array}{l}\text { Isna Wardiana } \\
\text { Ikbal } \\
\text { Nur Handayani } \\
\text { Riska }\end{array}$ \\
\hline 6 & $\begin{array}{l}\text { Andi Reyserdi } \\
\text { Muhammad Lutfi } \\
\text { Alvin. }\end{array}$ \\
\hline 7 & $\begin{array}{l}\text { Nur Sadrina Istiqomah } \\
\text { Muhammad Arfandi } \\
\text { Agung. }\end{array}$ \\
\hline
\end{tabular}

\section{Praktik}

Langkah-langkah yang dilakukan siswa dalam penerapan ragam hias flora pada keramik yaitu sebagai berikut:

\section{Membuat desain}

Langkah awal untuk menerapkan ragam hias flora pada keramik adalah membuat rancangan awal atau desain ragam hias. Dalam kegiatan praktik ini siswa kelas VIII K SMP Negeri 2 angkala Barat telah dibagi menjadi 7 


\section{imajinasisi}

kelompok yang setiap kelompok menyiapkan satu desain untuk satu keramik, berikut contoh gambarnya

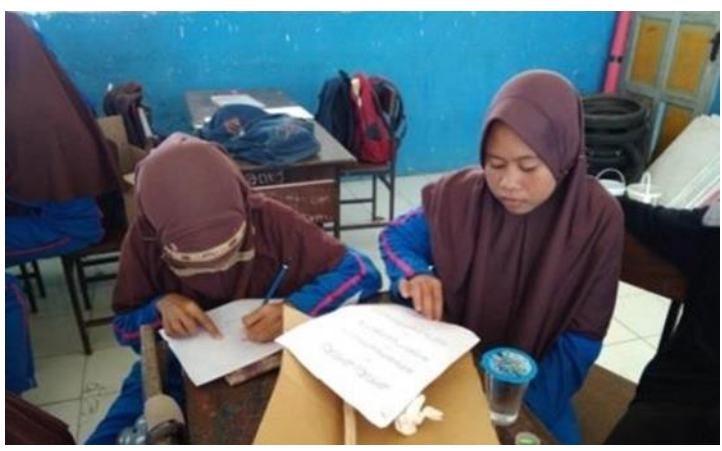

Gambar 1. Siswa membuat desain ragam hiasbersama teman kelompok (Dokumentasi: Mega Selfia H, September 2018)

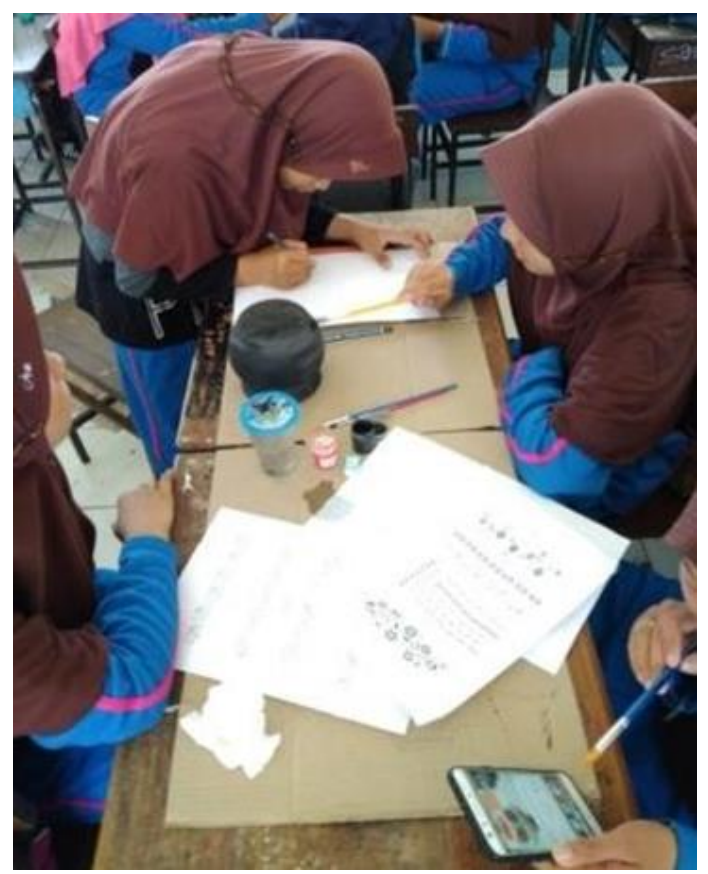

Gambar 2. Siswa membuat desain ragam hias bersama teman kelompok.

(Dokumentasi: Mega Selfia H, September 2018)

\section{Pemberian warna cat dasar pada keramik}

Langkah selanjutnya adalah memberi cat warna dasar pada keramik (gerabah) dengan menggunakan cat poster sesuai dengan warna yang disepakati anggota kelompok, berikut contoh gambarnya.

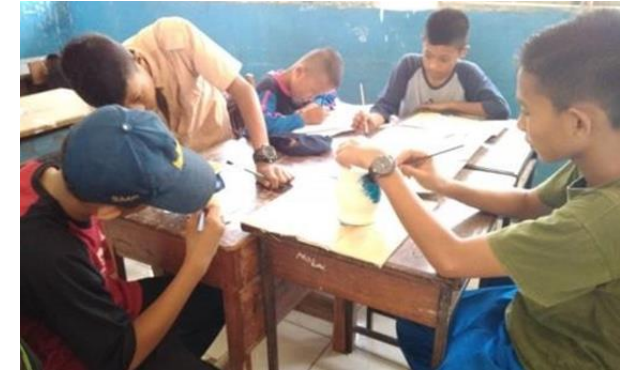

Gambar 3. Pemberian warna cat dasar pad keramik (Dokumentasi: Mega Selfia H, September 2018)

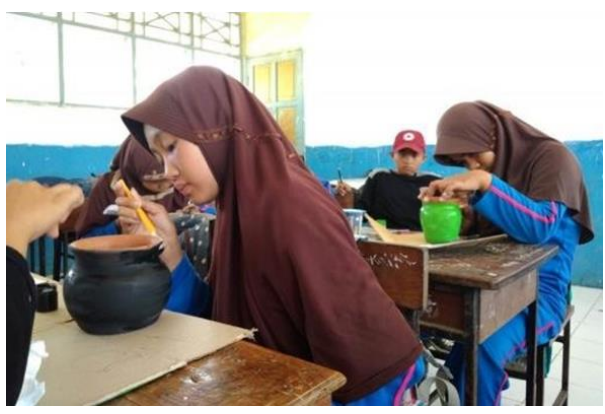

Gambar 4. Pemberian warna cat dasar pad keramik (Dokumentasi: Mega Selfia H September 2018)

\section{Memindahkan desain ke keramik (gerabah/kendi)}

Setelah cat dasar kering selanjutnya siswa memindahkan desain ke permukaan keramik (gerabah), berikut contoh gambarnya.

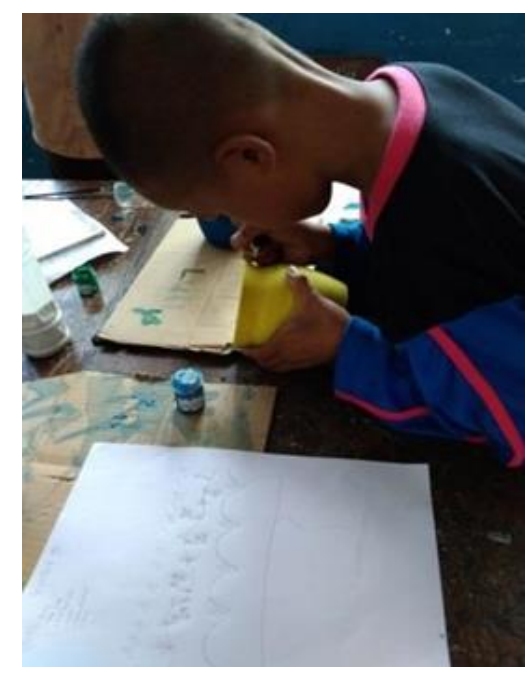

Gambar 5 Memindahkan desain pada keramik (Dokumentasi: Mega Selfia H, September 2018) 
Mega Selfia H $^{1}$, Yabu. M, PENERAPAN RAGAM HIAS FLORA PADA KERAMIK DALAM MATA PELAJARAN SENI BUDAYA BIDANG SENI RUPA BAGI SISWA SMP NEGERI 2 BANGKALA BARAT KABUPATEN JENEPONTO

\section{Mewarnai permukaan keramik}

Langkah selanutnya adalah mewarnai permukaan keramik berdasarkan desain yang telah dipindahkan sebelumnya untuk memperjelas motif yang telah dibuat, berikut contoh gambarnya.

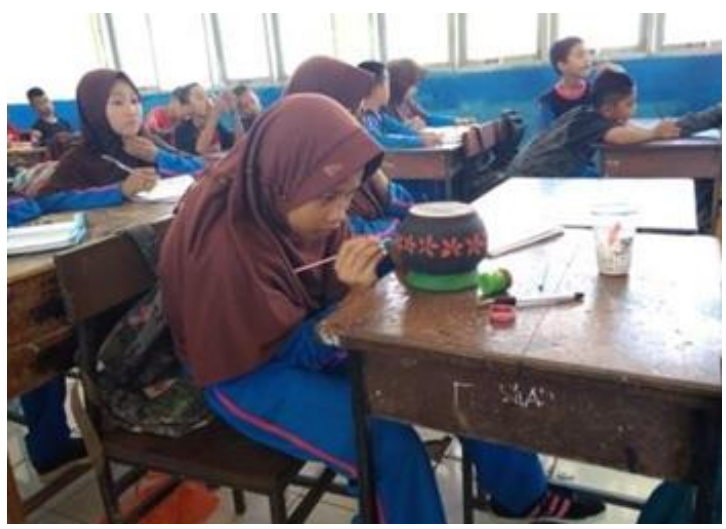

Gambar 6. Mewarnai permukaan keramik (Dokumentasi: Mega Selfia H, September 2018)

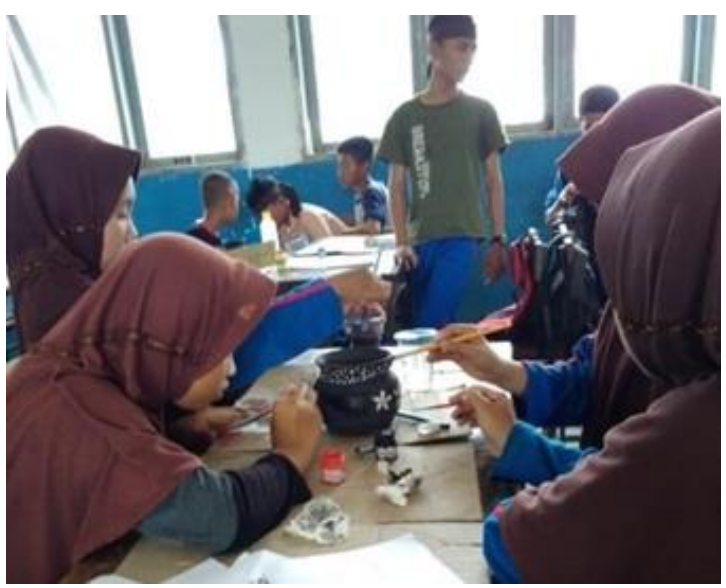

Gambar 7. Mewarnai permukaan keramik (Dokumentasi: Mega Selfia H, September 2018)

\section{Pembahasan}

Kegiatan praktik penerapan ragam hias flora pada keramik di kelas VIII K SMP Negeri 2 Bangkala Barat dilaksanakan secara berkelompok dengan masing-masing 1 buah keramik hias hasil karya siswa dan penilaiannya dapat dilihat pada gambar berikut:

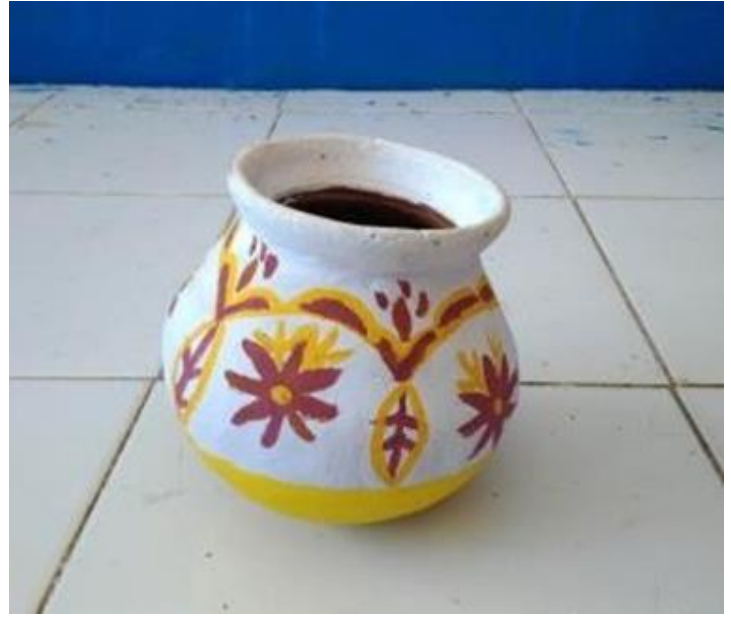

Gambar 8. Karya Kelompok 1 (Dokumentasi: Mega Selfia H, September 2018)

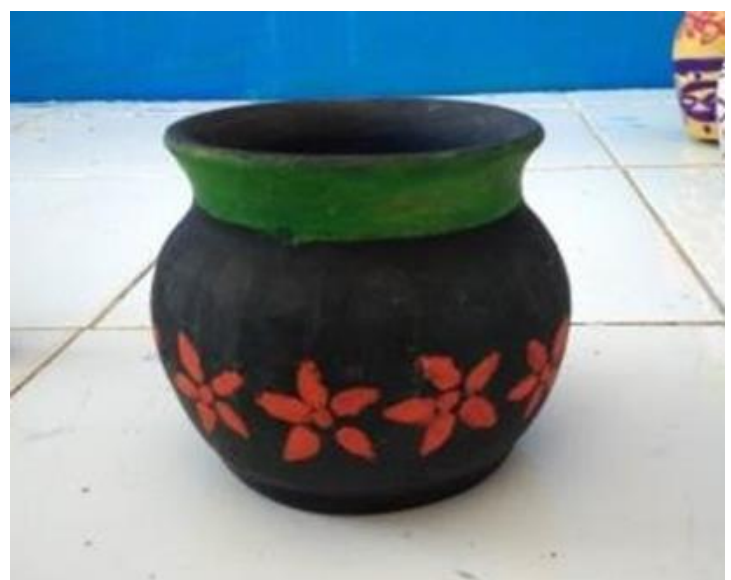

Gambar 9. Karya Kelompok 2 (Dokumentasi: Mega Selfia H, September 2018)

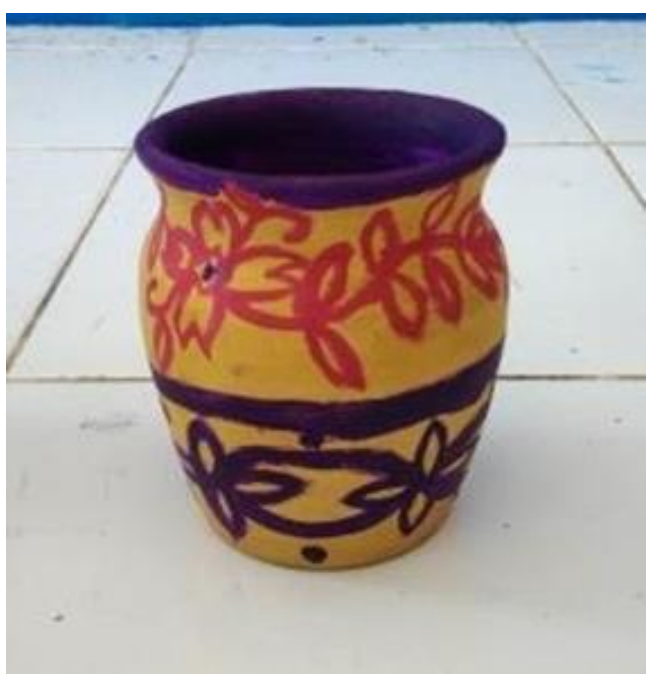

Gambar 10. Karya Kelompok 3 (Dokumentasi: Mega Selfia H, September 2018) 


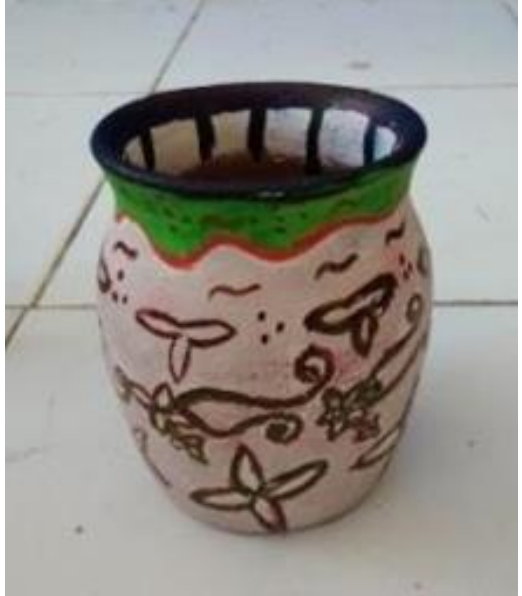

Gambar 11. Karya Kelompok 4 (Dokumentasi: Mega Selfia H, September 2018)

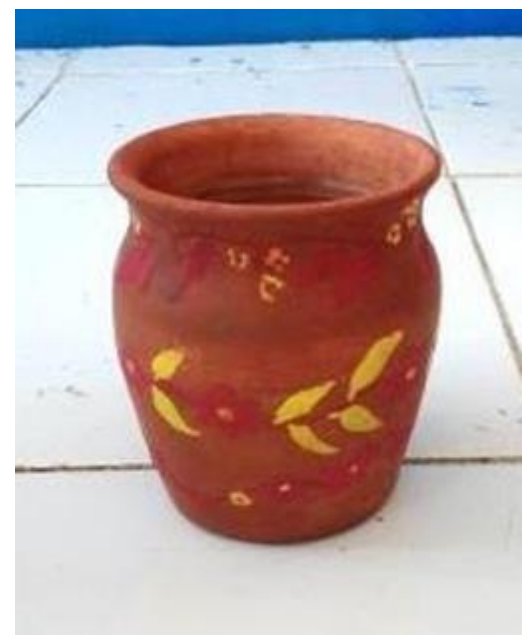

Gambar 12. Karya Kelompok 5 (Dokumentasi: Mega Selfia H, September 2018)

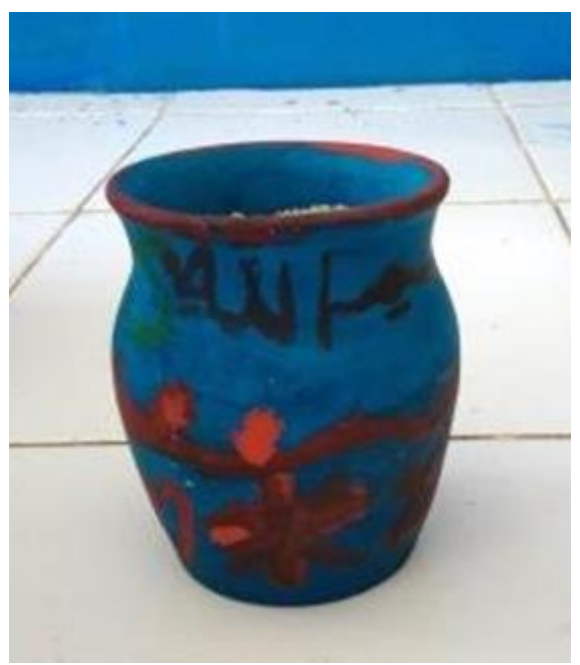

Gambar 13. Karya Kelompok 6 (Dokumentasi: Mega Selfia H, September 2018)

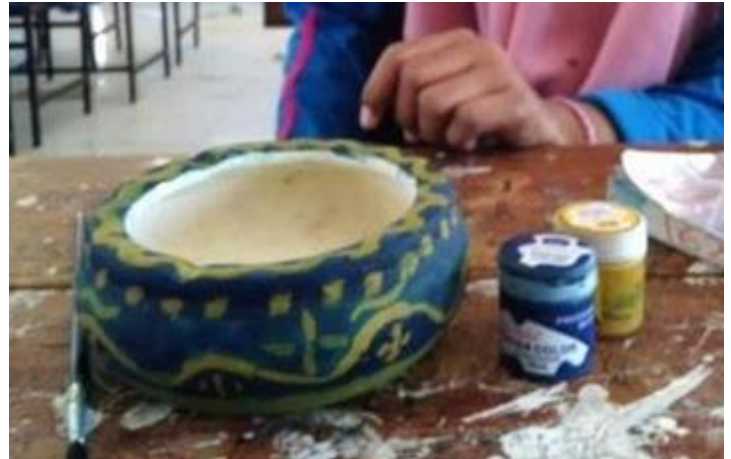

Gambar 14. Karya Kelompok 7 (Dokumentasi: Mega Selfia H, September 2018)

Dari hasil wawancara yang diadakan setelah praktik maka penulis mengambil beberapa kesimpulan dari beberapa pertanyaan tersebut mengenai kesulitan yang dihadapi siswa selama kegiatan praktik penerapan ragam hias flora pada keramik, yaitu dari 24 siswa yang hadir saat kegiatan belajar berlangsung ada 20 siswa yang mengaku kesulitan, dan 4 siswa yang tidak merasa kesulitan mempraktikkan ragam hias pada keramik. Diantara kesulitan yang dialami siswa selama kegiatan praktik berlangsung ada siswa yang kesulitan dalam membuat desain motif ragam hias flora yaitu 12 orang siswa, mewarnai keramik dengan menggunakan cat poster yaitu 1 orang siswa, dan 1 orang siswa yang kesulitan mencampur warna, dan 10 orang siswa mengalami kesulitan membuat desain motif ragam hias flora serta mewarnai keramik dengan cat poster.

Selanjutnya kesulitan lain yang dialami siswa adalam mewarnai keramik dengan mengikuti desain ragam hias di permukaan keramik. Namun dibalik kesulitan yang siswa alami, berdasarkan hasil wawancara terlihat bahwa siswa senang melakukan praktik penerapan ragam hias flora pada keramik yang juga dapat dilihat dari kesiapan bahan dan alat yang telah mereka siapkan bersama teman sekelompoknya.

Penelitian ini bertujuan untuk mengetahui langkah-langkah penerapan ragam hias flora pada keramik dalam mata pelajaran seni budaya bidang seni rupa bagi siswa kelas VIII K SMP Negeri 2 Bangkala Barat Kabupaten Jeneponto. Dalam suatu praktik terdapat langkah- langkah atau prosedur yang harus 
diikuti untuk memperoleh sebuah hasil atau karya. Terutama dalam praktik pembelajaran di sekolah, setelah memahami konsep penerapan ragam hias flora pada keramik (gerabah) siswa ditunjukan contoh dan langkah-langkah yang harus diikuti kemudian mengadakan menyediakan alat dan bahan untuk kegiatan praktik. Sedangkan langkah- langkah yang dilakukan siswa dalam penerapan ragam hias flora pada keramik yaitu; (1). Siswa yang telah dibagi secara berkelompok menyediakan alat dan bahan berupa cat poster, kuas, palet (gelas aqua bekas sebagai pengganti); (2). Siswa duduk secara berkelompok menentukan desain ragam hias flora yang akan diterapkan pada keramk dan memilih warna berdasarkan pilihan kelompoh pada selembar kertas HVS yang telah dibagikan, desain yang; (3). Setelah membuat desain motif ragam hias flora, salah satu siswa dari setiap kelompok mewarnai keramik (gerabah) dengan satu warna dasar yang telah dipilih sebelumnya; (4). Setelah cat dasar pada keramik mengering siswa membuat sketsa pada keramik (gerabah) mengikuti desain yang dibuat pada kertas HVS; (5). Selantutnya mewarnai motif ragamm hias yang masih berupa sketsa; (6) Setelah mewarnai siswa menyelesaikan pewarnaan, keramik dibiarkan beberapa menit hingga kering kemudian dikumpul di depan kelas untuk penilaian karya oleh guru seni budaya.

Berdasarkan tujuan yang ingin dicapai penulis maka dari hasil penelitian yang dilakukan hasilnya dari 24 siswa $57,17 \%$ yaitu sebanyak 13 siswa mengetahui langkahlangkah penerapan ragam hias flora pada keramik dalam mata pelajaran seni budaya bidang seni rupa bagi siswa kelas VIII $\mathrm{K}$ SMPN 2 Bangkala Barat Kabupaten Jeneponto sementara yang tidak begitu paham dengan langkah- langkah yang seharusnya adalah 45,83\% sebanyak 1 siswa. Berdasarkan hasil pengamatan penulis selama kegiatan praktik penerapan ragam hias flora pada keramik di kelas VIII K SMPN 2 Bangkala Barat $62,5 \%$ siswa mengetahui alat dan bahan dalam penerapan ragam hias flora pada keramik dan $37,5 \%$ tidak begitu mengetahui.

Berdasarkan hasil analisis data wawancara dari jumlah 24 siswa yang menjadi sampel ditemukan fakta bahwa kendala yang dialami siswa kelas VIII K SMP Negeri 2 Bangkala barat ketika proses praktik penerapan ragam hias flora pada keramik yaitu: (1). Membuat desain motif ragam hias flora (50\%); (2). Mewarnai keramik dengan cat poster $(4,17 \%)$; (3). Mencampur warna (4,17\%); (4). Membuat desain motif ragam hias flora dan Mewarnai keramik dengan cat poster $(41,66 \%)$. Sedangkan kendala yang dialami guru seni budaya dalam proses praktik penerapan ragam hias flora pada keramik di kelas VIII K SMP Negeri 2 Bangkala Barat yaitu, penyediaan alat dan bahan untuk praktik, kendala ini berdasarkan pernyataan guru seni budaya saat wawancara dan setelah kegiatan praktik berlangsung peneliti menemukan bahwa pernyataan ini benar, saat kegiatan praktik berlangsung masih banyak siswa yang meminam bahan dari teman- temannya dan bukan milik sendiri.

\section{SIMPULAN DAN SARAN Kesimpulan}

Kegiatan praktik penerapan ragam hias flora pada keramik dalam mata pelajaran seni budaya bidang seni rupa di kelas VIII K SMP Negeri 2 Bangkala Barat dilaksanakan dengan mengikuti langkah-langkah yang benar berdasarkan arahan guru dalam proses pembelajaran dengan karya yang cukup memuaskan yang diperoleh siswa dalam melaksanakan kegiatan praktik penerapan ragam hias flora pada keramik khususnya gerabah dengan media cat poster. Meskipun masih mengalami kesulitan dalam membuat desain motif ragam hias flora namun siswa dapat menyelesaikan sebuah karya secara berkelompok dengan hasil yang cukup memuaskan

\section{Saran}

Berdasarkan hasil dari kesimpulan yang telah diuraikan tersebut, maka penulis menyarangkan beberapa hal sebagi berikut:

1. Rekan mahasiswa khususnya seni rupa agar kiranya hasil penelitian ini dapat dijadikan refrensi dalam menambah wawasan terkait langkahlangkah penerapan ragam hias flora pada keramik. 
2. Diharapkan kepada pihak sekolah/pihak terkait agar dapat memberikan fasilitas pendukung; atau penyediaan media pembelaaran serta dorongan moril dan semangat kepada siswa sehingga dapat melaksanakan kegiatan praktik guna menambah wawawan dan pemngalaman prakik kepada siswa mengenai langkahlangkah penerapan ragam hias flora pada keramik khususnya gerabah.

3. Diharapkan kepada Guru agar memberikan praktik mengerjakan ragam hias flora pada bahan keras terutama pada keramik khususnya gerabah agar siswa dapat menghargai kesenian nusantara yang ada sekitarnya.

4. Diharapkan kepada siswa SMP Negeri 2 Bangkala Barat agar dapat termotivasi dengan pelaksanaan kegiatan praktik di dalam kelas agar mampu menerapkan ragam hias flora pada keramik lebih baik lagi.

\section{DAFTAR PUSTAKA}

Haling, Abd., Abdul. Salam dan Arnidah. 2007. Perencanaan Pembelajaran. Makassar: Badan Penerbit UNM

Hadi, Amirul \& Haryono. 2005.

Metodologi Penelitian Pendidikan. Bandung: CV Pustaka Setia.

Huda, K. 2007. Ragam Hias pada Makam Kuno Raj-Raja Luwu di Lakkoe Kabupaten Luwu, SKripsi. FBS Universitas Negeri Makassar.

$\begin{array}{llll}\text { Hoop V. } & \text { D. }\end{array}$ Indonesische siermotieven. Koninklijk Bataviaasch Genootscap Van Kusten En Waten Schappen.

Iskandar. 2008. "Metodologi Penelitian Pendidikan dan Sosial". Jakarta: GP Prees.

Moeliono, A. M, dkk. 1990. Kamus Besar Bahasa Indonesia. Jakarta: Balai Pustaka.

Purnomo, Eko., dkk. 2014. Buku Seni Budaya SMP/MTS kelas VIII. Jakarta: Kementrian Pendidikan Nasional.

Prajitno, N. H. 2012. Ragam Hias Makam

Raja-raja Alla di Desa Taulo
Kecamatan alla Kabupaten Enrekang. Skripsi. FSD Universitas Negeri Makassar.

Suryabrata, Sumadi. 2012. Metodologi Penelitian. Jakarta: PT RajaGrafindo Persada.

Soeroto, M. 2003. Dari Arsitektur Tradisional Menuju Arsitektur Indonesia. Jakarta: Ghalia Indonesia.

Toekio, S. M. 1987. Mengenal Ragam Hias Indonesia. Bandung: Angkasa.

Wahid, A. K. 1990. Sejarah Seni Rupa Indonesia. FPBS IKIP Ujung Pandang.

Wijana. 1994.”Studi Tentang Kerajinan

Gerabah Karya Zainal Mahmud Di

Tumenggungan

Lamongan".Skripsi tidak diterbitkan. Surabaya: JSRK FPBS IKIP.

Website:

http://www.mikirbae.com/2015/01/penera pan-ragam-hias-pada-bahan-

keras.html?m=1 (di akses pada 03:07 17/04/18)

sumber gamabar: Pinteres 